\title{
Profile of male adolescents with conduct disorder on intellectual efficacy, cognitive flexibility, cognitive coping, impulsivity and alexithymia: A comparison with high-risk controls
}

\section{S. Pihet \\ M. Suter \\ O. Halfon \\ P. Stephan}

Service Universitaire de Psychiatrie de l'Enfant et de l'Adolescent, Unité de Recherche

Lausanne

SWITZERLAND

ABSTRACT - Background and Objectives: To specify which of the documented cognitive and emotional deficits characterize adolescents with conduct disorder (CD) compared with high-risk controls.

Methods: High-risk adolescent males with and without CD were compared on intellectual efficiency, cognitive flexibility, impulsivity, alexithymia, and cognitive coping strategies. Substance use was controlled for in analyses.

Results: Both groups showed normal intellectual efficiency and cognitive flexibility, as well as heightened alexithymia and behavioral impulsivity. Youths with CD evidenced more self-defeating and black-and-white thinking under stress, and more acting-out under negative affect, than those without CD.

Conclusions: Deficits specific to $\mathrm{CD}$ resided in facets of emotional functioning and cognitive coping that might be targeted by a coping skills intervention.

Received: 16 March 2011

Revised: 5 April 2012

Accepted: 31 May 2012 


\section{Background and objectives}

Conduct disorder (CD) is one of the most common mental disorders in juvenile offenders ${ }^{1}$, and may thus be an important target for the application of Juvenile Court Acts, for example the Swiss and German ones, which put a strong emphasis on education and treatment in response to juvenile delinquency. In this perspective, skills training programs represent cost-effective interventions that could be implemented in facilities accommodating juvenile offenders. However, the currently available evidence-based programs, which mostly focus on social skills, are scarce and have demonstrated limited efficacy ${ }^{2,3}$. The emotional or cognitive deficits that have been shown to be associated with offending or $\mathrm{CD}^{4,5}$ could be good candidates for alternative or additional skills training programs. Yet to date most studies identifying them compared extreme groups, i.e. CD diagnosed adolescents or incarcerated juvenile offenders with pupils of the regular school curriculum, without controlling for important confounding factors such as comorbid mental disorders, and particularly substance use disorders. Some of the differences we will review might thus be overestimated.

One century of research has repeatedly established the existence of a negative relationship between IQ and offending or CD, but only in the past decades has extensive examination suggested it to hold only for verbal $\mathrm{IQ}^{6}$. Given the typically low level of academic achievement of delinquent youths, this finding could be partly explained by their lack of exposure to the kind of information assessed by verbal IQ tests ${ }^{7}$. Measures of intelligence unrelated to education (e.g. non verbal intelligence), or culture-free tests, might thus fit better this population. More so as research using them found no differences between youths with and without $\mathrm{CD}^{8,9}$.
Findings from extensive scientific research focusing on executive functions, suggest that two types of dysfunctions are strongly involved in delinquency. Firstly, deficits in cognitive flexibility ${ }^{10}$, in particular the ability to shift cognitive set according to changing contingencies, have been described using the Wisconsin Card Sorting Test ${ }^{11}$ : adolescents with CD seem to perform more poorly than community controls ${ }^{5,12}$, although some found them to perform equally well ${ }^{13}$. Secondly, deficits in inhibition are well documented ${ }^{14-16}$, in particular in some aspects of behavioral inhibition, such as the ability to refrain from responding before the stimulus is fully processed, as measured by the behavioral task of Immediate and Delayed Memory, IMT/DMT ${ }^{17}$ : this type of impulsive behavioral response was observed more frequently in adolescents with disruptive behavior ${ }^{18,19}$ or with $\mathrm{CD}^{20,21}$, compared with community adolescents.

Impairments in emotional regulation also appear to play an important role in delinquent behavior. Apart from the executive function research approach mentioned above, impulsivity has also been extensively investigated in offenders as a personality trait ${ }^{22,23}$, using questionnaire measures. Higher levels of trait impulsivity were consistently observed in adolescent offenders ${ }^{6,24}$ or with $\mathrm{CD}^{25}$ compared to adolescents from the general population. Nevertheless, using more differentiated measures of trait impulsivity such as the UPPS scale ${ }^{26}$, externalizing problems were found to be associated with only some of the four investigated dimensions ${ }^{27}$.

Another important concept related to emotional regulation, though more scarcely investigated, is alexithymia, meaning the inability to recognize and describe feelings, and an externally oriented way of thinking ${ }^{28}$. Higher levels of alexithymia have been documented in male adolescent offenders, compared to community adolescents ${ }^{29,30}$. However, these results remain to be replicated in adolescents with CD. 
Constructive thinking is yet another promising concept, covering the use of functional cognitive coping styles in stressful situations $^{31}$ : adolescent girls with $\mathrm{CD}$ reported to use less constructive and more destructive coping strategies than their counterparts from the general population ${ }^{32}$. However, this result has not yet been replicated in boys.

Although the literature reviewed has shed light on features of cognitive and emotional functioning that might characterize adolescent offenders and, in some cases, adolescents with $\mathrm{CD}$, they share a number of methodological shortcomings. Firstly, most of the studies have used control groups consisting of community adolescents, recognized as presenting, among other potentially confounding factors, a much lower prevalence of psychiatric disorders (particularly substance use disorders $)^{1,33}$. The latter were often not controlled for in analyses, and might be responsible for part or all of the observed differences between the two groups. Secondly, cognitive and emotional deficits have predominantly been studied separately, despite a growing body of evidence underlining their interdependence ${ }^{34,35}$.

The present study thus aimed at assessing simultaneously the reviewed cognitive and emotional deficits, comparing male adolescents with $\mathrm{CD}$ to high-risk adolescents presenting similar rates of other psychiatric disorders, and controlling for problematic substance use in all analyses. We expected some of the documented differences not to be replicated in this more stringent design.

\section{Methods}

\section{Participants}

Adolescent males aged 12 to 18 years were recruited in three leisure centers, two foster care units and two institutions for juvenile offenders, with exclusion criteria of lifetime presence of psychotic disorders, mental retardation, and insufficient French language skills. The sample is composed of 78 youths, 39 scoring above the clinical cut-off on the Pedersen questionnaire for CD (see "Measures"), constituting the CD group ( $\mathrm{M}=4.90$ \pm 1.99 ), and 39 scoring below the cut-off, constituting the non-CD group $(\mathrm{M}=0.85 \pm$ $0.87, \mathrm{~d}=2.82$; i.e. the difference in frequency of delinquent behavior between the two groups is very large). In the $\mathrm{CD}$ and non $\mathrm{CD}$ groups, respectively 10 and $40 \%$ of the youths were recruited from the leisure centers, 87 and $58 \%$ from institutions for juvenile offenders and 3 and $2 \%$ from foster care units. The two groups did not differ significantly on most socio-demographic variables and on psychiatric comorbidity rates (see Table 1).

\section{Measures}

Conduct disorder. The 17-item self-report questionnaire of Pedersen assesses delinquent behaviors closely related to criteria for CD in DSM-IIIR; its psychometric properties are well established ${ }^{36}$. This measure was chosen for its focus on delinquent behaviors that could be planned or impulsive in nature, ensuring its full independence from the selfreport measures of impulsivity. Answers are given on a 6-point scale based on the frequency of the delinquent behavior during the previous 12 months: $1=$ never, $2=$ once, $3=$ 2 to 5 times, $4=6$ to 10 times, $5=11$ to 50 times and $6=$ more than 50 times. Items range from common adolescent behaviors considered problematic only when high in frequency to serious ones that are problematic even when infrequent, for which different cut-off have been proposed according to their severity ${ }^{37}$. The cut-off point is 6 (more than 50 times) for items investigating minor problem behavior (e.g. "sneaked into bus, train, cinema, etc. without paying"), 5 (11 
Table 1

Socio-demographic information and comorbidity rates of the sample

\begin{tabular}{lllll} 
& non- $\mathrm{CD}(\mathrm{N}=39)$ & $\mathrm{CD}(\mathrm{N}=39)$ & Test & Sig \\
\cline { 2 - 3 } & $\mathrm{M} \pm \mathrm{SD}$ or $\%$ & $\mathrm{M} \pm \mathrm{SD}$ or $\%$ & & .179 \\
\hline Age & $15.71 \pm 1.21$ & $16.12 \pm 1.43$ & $\mathrm{t}=-1.35$ & .643 \\
Migrants & 43.6 & 56.4 & $\chi^{2}=8.77$ & .03 \\
School dropouts & 17.9 & 46.3 & $\chi^{2}=10.55$ & .032 \\
Intact families & 46.2 & 30.1 & $\chi^{2}=10.90$ & .207 \\
Biological parents & 97.4 & 92.7 & $\chi^{2}=.32$ & .571 \\
Living with both parents/one & $53.9 / 43.7 / 2.6$ & $34.2 / 60.9 / 2.4$ & $\chi^{2}=9.58$ & .295 \\
parent/foster care (life) & $43.6 / 36.0 / 15.4$ & $17.0 / 46.4 / 26.8$ & $\chi^{2}=11.59$ & .237 \\
Living with (see above, current year) & 7.7 & 12.2 & $\chi^{2}=10.22$ & .421 \\
Father unemployment & 23.1 & 22.0 & $\chi^{2}=9.57$ & .479 \\
Mother unemployment & 12.8 & 23.1 & $\chi^{2}=1.14$ & .285 \\
Depression (current year) & 46.2 & 64.9 & $\chi^{2}=2.69$ & .101 \\
Depression (lifetime) & 17.9 & 15.4 & $\chi^{2}=0.09$ & .761 \\
Suicide attempts & 28.2 & 23.1 & $\chi^{2}=0.35$ & .557 \\
Self-injury & 35.0 & 50.0 & $\chi^{2}=1.69$ & .188 \\
Alcohol (dependency) & 60.0 & 74.3 & $\chi^{2}=1.38$ & .189 \\
Illegal substances (dependency) & & &
\end{tabular}

times or more) for items investigating moderate problem behavior (e.g. "stolen money or objects from someone in your family"), and 3 (2 times or more) for items investigating serious problem behavior (e.g. "stolen a car or a motorcycle"). Consistent with DSM criteria and previous validation of this strategy in a sample of over 10,000 community adolescents $^{37}$, our CD group consisted of participants scoring at or above the mentioned cut-off on three or more items. In the present sample, this questionnaire's Cronbach $\alpha$ is .86 .

Substance Use Disorder (SUD). For control purposes, we used the severity index of the Dep-Ado ${ }^{38,39}$, a screening interview evaluating the problematic use of alcohol and other substances, over the last 12 months. Its French version ${ }^{40}$ has a sensitivity of $95.1 \%$ and a specificity of $68.9 \%$ when compared with the M.I.N.I. ${ }^{41}$.
Non verbal intellectual efficiency. The Raven Progressive Matrices ${ }^{42}$ comprises 60 problems of increasing complexity. Its total score varies between 0 and 60 . Scores under 30 indicate intellectual deficiency. This scale has shown high internal consistency, and acceptable to excellent convergent validity ( $r$ s between .54 and .86) with other measures of intelligence in children and adolescents ${ }^{42}$.

Cognitive flexibility. The Wisconsin Card Sorting Test (WCST) was developed to measure abstract reasoning and cognitive flexibility ${ }^{11}$. The total number of errors was used to control that participants understood the task, and the number of perseverative error to assess the ability to shift cognitive set according to changing contingencies ${ }^{43}$.

Behavioral impulsivity. The Immediate Memory Task and Delayed Memory Task, 
IMT/DMT $^{17}$, is a computerized Continuous Performance Task measuring attention, memory, and impulsive response style. The ratio of commission errors to correct detections is considered the primary measure of deficits in behavioral inhibition, particularly the ability to refrain from responding before the stimulus is fully processed, with the advantage of correcting for individual differences in attention or general performance ${ }^{44}$.

Trait impulsivity. The UPPS Impulsive Behavior Scale ${ }^{26}$ is a 45 -item self-report questionnaire, assessing four distinct but related dimensions of impulsivity: Urgency, (lack of) Premeditation, (lack of) Perseverance, and Sensation Seeking. Answers are rated on a 4-point scale ranging from $1=$ total disagreement to $4=$ total agreement. Its French adaptation has demonstrated good internal consistency with as in the .80 range $^{45}$, which was confirmed in our sample ( $\alpha$ s from .76 to .78).

Alexithymia. The Toronto Alexithymia Scale, TAS- $20^{46}$ is a 20 -item self-report questionnaire. Responses are given on a 5-point scale ranging from 1 = complete disagreement to $5=$ complete agreement. It comprises three subscales: Difficulty identifying feelings, Difficulty describing feelings, and Externally oriented thinking. Scores above 56 reflect alexithymia, those under 44 reflect its absence ${ }^{47}$. The French version has satisfactory psychometric properties, with as above $.70^{48}$. In the present sample, internal consistency was acceptable for Difficulty identifying feelings ( $\alpha=$.70.) and Difficulty describing feelings ( $\alpha=.62$ ), but low for Externally oriented thinking $(\alpha=.32)$.

Constructive Thinking. The Constructive Thinking Inventory, $\mathrm{CTI}^{31}$ is a 108 -item selfreport questionnaire describing cognitive strategies used to handle daily-life problems ${ }^{31}$. It comprises one global scale (Global Constructive Thinking), and six specific scales: two constructive (Emotional Coping, Behavioral Coping) and four destructive ones (Personal Superstitious Thinking, Categorical Thinking, Esoteric Thinking, Naive Optimism). The French version has shown a good internal consistency, with $\alpha$ s ranging from .70 to $.88^{49}$ which was confirmed in the present sample ( $\alpha$ s from .62 to .80).

Psychiatric comorbidity. The French short version of the Mini International Neuropsychiatric Interview, M.I.N.I ${ }^{41}$, a structured diagnostic interview for the standardized investigation of Axis I diagnosis of DSM-IV ${ }^{50}$, was used to assess mood disorders (depression), substance/alcohol abuse and dependency, self-injury and suicide attempts. It has good psychometric properties ${ }^{51}$.

\section{Procedure}

Formal permission was obtained from the recruitment centers and the Juvenile Court, which holds the legal responsibility for the adolescents accommodated by institutions for juvenile offenders. Written informed consent was obtained from each participant after providing them with a complete description of the study. The confidentiality of answers was guaranteed. Data were collected by a trained psychologist during a single individual session of about two hours. Data collection took place in the institutions for juvenile offenders for youths recruited there, and in the Research Unit for other youths, who were reimbursed for their travel expenses and received a 50 $\mathrm{CHF}$ voucher for their participation. Approval was obtained from the ethics committee.

\section{Data analysis}

Two MANCOVAs, with CD versus non$\mathrm{CD}$ as a two-level between factor, and substance use problems (Dep-Ado severity 
index) as a covariate, were carried out on 1) the total and 2) the subscale scores of the CTI, the TAS-20, the UPPS, the WCST, the IMT/DMT and the Raven. Relations between the cognitive and emotional variables were explored using partial correlations, controlling for group (CD versus non-CD) and substance use problems.

\section{Results}

\section{Total scores}

Regarding the total scores ${ }^{*}$ for the Raven Progressive Matrices, the WCST, the IMT/ DMT ratios, the TAS-20 and the CTI, no significant difference emerged between the $\mathrm{CD}$ and non-CD groups $\left(\mathrm{F}_{(7,65)}=1.26, \mathrm{p}=.282\right.$; see Table 2). Results remained identical when further controlling for depression. In comparison with normative values, both groups scored in the normal range on the Raven Progressive Matrices ${ }^{42}$ and on the $\mathrm{WCST}^{11}$, but demonstrated higher levels of behavioral impulsivity ${ }^{18}$, speaking for a normal non verbal intellectual efficacy and cognitive flexibility, but a decreased behavioral inhibition independent of CD. High levels of alexithymia were further observed in both groups: their means were above the clinical cut-off of 56, with $66.7 \%$ and $56.4 \%$ of the youths scoring above the clinical cut-off in the CD and non$\mathrm{CD}$ groups, respectively. Both groups also scored relatively low on Global Constructive Thinking ${ }^{49}$, indicative of a slightly dysfunctional cognitive coping in our sample, unrelated to $\mathrm{CD}$.

To explore finer-grained differences, a MANCOVA was further performed on the six specific scales of the CTI, the four dimensions of the UPPS and the three subscales of the TAS-20. Its results pointed to significant and substantial differences between the $\mathrm{CD}$ and non- $\mathrm{CD}$ groups $\left(\mathrm{F}_{(13,63)}=\right.$ $2.61, \mathrm{p}=.006, \eta_{\text {partial }}^{2}=.35$ ), with $35 \%$ of the variance explained by the group differences, which corresponds to a large effect. Subsequent univariate analyses revealed significant differences for some specific scales of the CTI and UPPS, but no significant differences for the three subscales of the TAS-20.

Table 2

Differences between the CD and non-CD groups on the total scores

\begin{tabular}{lrrrrrrr} 
& \multicolumn{2}{c}{ non-CD $(\mathrm{N}=39)$} & \multicolumn{2}{c}{$\mathrm{CD}(\mathrm{N}=39)$} & & \multirow{2}{*}{$\mathrm{F}_{(1,71)}$} & Sig \\
\cline { 2 - 5 } & \multicolumn{1}{c}{$\mathrm{M}$} & \multicolumn{1}{c}{$\mathrm{SD}$} & \multicolumn{1}{c}{$\mathrm{M}$} & \multicolumn{1}{c}{$\mathrm{SD}$} & & \\
\hline Intellectual efficiency (Raven) & 41.32 & 8.38 & 45.36 & 6.37 & 2.51 & .118 \\
Global Constructive Thinking (CTI) & 94.63 & 9.50 & 91.86 & 11.44 & 0.35 & .554 \\
Alexithymia (TAS-20) & 56.95 & 10.20 & 58.73 & 9.47 & 0.37 & .543 \\
Number of errors (WSCT) & 34.21 & 20.88 & 25.08 & 15.81 & 2.94 & .091 \\
Number of perseverative errors (WSCT) & 14.95 & 9.92 & 11.56 & 9.26 & 1.16 & .286 \\
IMT ratio & 0.56 & 0.13 & 0.58 & 0.19 & 0.38 & .538 \\
DMT ratio & 0.58 & 0.22 & 0.63 & 0.31 & 0.40 & .529 \\
\hline
\end{tabular}

\footnotetext{
* The UPPS was not included in this analysis because no total score can be derived from it.
} 


\section{Constructive Thinking}

Significant effects emerged for two of the six specific scales of the CTI (see Table 3): youths with $\mathrm{CD}$ scored higher than their nonCD counterparts on Personal Superstitious Thinking and Categorical Thinking, while the groups did not differ on the four other specific scales. Adolescents with CD reported a less flexible thinking style in stressful situations (such as "I tend to classify people as either for me or against me"), for which group membership explained $17 \%$ of the variance. They further appeared more inclined to think in a magical pessimistic or self-defeating way (such as "if something good happens to me, something bad will follow"), group membership explaining $9 \%$ of the variance. Again, results remained identical after controlling for depression.

Partial correlation controlling for group differences and substance problematic use showed these two cognitive coping styles were associated $(p r=.38, p=.001)$, and both correlated positively with alexithymia scores (for Personal Superstitious Thinking: $p r=$ $.44, p<.001$ and for Categorical Thinking: $p r$ $=.28, p=.018)$. Categorical Thinking was further related to increased perseverative errors on the WCST $(p r=.35, p=.005)$, suggesting it reflects a combination of cognitive and emotional features.

\section{Impulsivity}

Regarding the four dimensions of the UPPS (see Table 3), adolescents with CD scored significantly higher than non-CD youths on Urgency, indicating for the former a stronger tendency to act-out when confronted with negative affects. Group membership explained $9 \%$ of the variance. This result remained identical after controlling for depression. Urgency was further found to be

Table 3

Differences between the CD and non-CD groups on the specific scales of the CTI (1-6) and UPPS (7-10) and TAS-20 (11-13)

\begin{tabular}{|c|c|c|c|c|c|c|c|}
\hline & \multicolumn{2}{|c|}{ non- $\mathrm{CD}(\mathrm{N}=39)$} & \multicolumn{2}{|c|}{$\mathrm{CD}(\mathrm{N}=39)$} & \multirow{2}{*}{$\mathrm{F}_{(1,75)}$} & \multirow{2}{*}{ Sig } & \multirow{2}{*}{$\eta_{\text {partial }}^{2}$} \\
\hline & $\mathrm{M}$ & SD & M & $\mathrm{SD}$ & & & \\
\hline 1. Emotional Coping & 81.56 & 10.79 & 78.26 & 13.76 & 0.11 & .741 & 0.00 \\
\hline 2. Behavioral Coping & 46.67 & 7.33 & 47.00 & 6.30 & 0.15 & .698 & 0.00 \\
\hline 3. Personal Superstitious Thinking & 18.82 & 5.16 & 22.26 & 5.26 & 7.68 & .007 & 0.09 \\
\hline 4. Categorical Thinking & 45.56 & 7.09 & 51.33 & 7.87 & 14.81 & $<0.001$ & 0.17 \\
\hline 5. Esoteric Thinking & 29.15 & 7.44 & 30.08 & 10.78 & 0.05 & .817 & 0.00 \\
\hline 6. Naive Optimism & 48.26 & 11.36 & 47.28 & 8.66 & 0.45 & .833 & 0.00 \\
\hline 7. (Lack) of Premeditation & 25.12 & 5.37 & 26.54 & 5.25 & 1.02 & .317 & 0.01 \\
\hline 8. Sensation Seeking & 38.03 & 5.34 & 37.10 & 6.13 & 1.77 & .187 & 0.02 \\
\hline 9. Urgency & 31.12 & 5.08 & 35.62 & 5.26 & 7.36 & .008 & 0.09 \\
\hline 10. (Lack) of Perseverance & 21.17 & 4.89 & 23.23 & 4.24 & 2.13 & .149 & 0.03 \\
\hline 11. Difficulty Identifying Feelings & 18.72 & 5.45 & 20.78 & 5.98 & 0.75 & .388 & 0.10 \\
\hline 12. Difficulty Describing Feelings & 16.28 & 5.07 & 15.51 & 3.42 & 0.47 & .494 & 0.06 \\
\hline 13. Externally Oriented Thinking & 22.10 & 4.45 & 22.10 & 3.66 & 0.40 & .531 & 0.05 \\
\hline
\end{tabular}


associated with alexithymia $(p r=.45, p<$ $.001)$ and self-defeating thinking $(p r=.26, p$ $=.027$ ). No significant differences were observed on the other three dimensions.

\section{Conclusions}

The present study aimed to examine some deficits in cognitive and emotional functioning documented in adolescents with CD using a more stringent design, which controlled for problematic substance use, and used a highrisk comparison group with similar rates of mental disorders, migrant background, disrupted families and unemployed parents, therefore avoiding many of the potential confounding factors in previous studies.

We believe our more controlled design is responsible for our finding of similarly high alexithymia levels in both groups, suggesting alexithymia is not specific to $\mathrm{CD}$, in line with high levels also documented in adults with depression $^{52}$ or borderline personality disorder $^{53}$. Our adolescents with CD also didn't differ from their non-CD counterparts on nonverbal intellectual efficiency, both groups scoring in the normal to superior range, although the CD group had higher rates of school dropout. This confirms the results of the few studies that examined performance IQ separately from verbal one ${ }^{6}$, or focused on the performance versus verbal IQ discrepancy $^{54,55}$, suggesting that $\mathrm{CD}$ is not primarily related to non verbal intellectual deficits.

As to cognitive flexibility, we did not replicate results from studies comparing more contrasted groups of adolescent offenders and community youths ${ }^{5,12}$, in that we observed no significant differences on the WCST. Remarkably, both of our groups scored in the normality range, consistent with another null result obtained between community and CD youths after adjusting for verbal IQ ${ }^{13}$. However, we cannot rule out the possibility that both of these null results are due to the studies not taking into account callous-unemotional traits, which are known to be associated with impairments in the formation of stimulus-reinforcement associations $^{56,57}$. On the other hand, our CD youths self-reported a significantly reduced cognitive flexibility in stressful situations, compared to high-risk youths without $\mathrm{CD}$, replicating differences found between community girls and their counterparts with $\mathrm{CD}^{32}$. This tendency for black-and-white thinking when under stress seems to capture a specific coping style, which appears to be associated with reduced emotional information processing and cognitive flexibility, and might constitute an interesting specific target for a coping skills intervention.

Impulsive behavioural responses were higher than normative values in both of our groups; however no significant differences were found between them, even if adolescents with $C D$ reported a significantly stronger tendency to act-out when experiencing negative emotions than those without CD. Positive relationships between trait impulsivity and deviant behavior are well documented in community samples (e.g. ${ }^{24,58-60}$ ). Still it had only been demonstrated in a limited number of small samples of clinical adolescents with disruptive behaviours ${ }^{21}$, or CD associated with substance abuse ${ }^{61}$. This study is thus, to our knowledge, the first demonstration of higher acting-out in $\mathrm{CD}$ adolescents compared with youths presenting similar rates of SUD, depression, self-harm, and suicide attempts, after controlling for the severity of problematic substance use and depression. Unfortunately, ADHD and borderline personality traits were not assessed in this sample. Given that impulsivity is as well a predominant fea- 
ture in these disorders ${ }^{62}$, further studies taking them into account are needed. So far, our findings suggest that acting-out is frequent in $\mathrm{CD}$ adolescents and is related to alexithymia and self-defeating thinking. This constellation of quick and disproportionate reactions, in the context of difficulties in identifying and expressing feelings and lack of confidence in oneself, may constitute a second promising target for a coping skills intervention specific to $\mathrm{CD}$. The heightened self-defeating thinking found in our CD male adolescents had previously been documented in small groups of girls with $\mathrm{CD}$, but also with SUD, compared to community girls ${ }^{32}$. Further systematic comparisons of clinical groups are needed to confirm our results as to deficits characterizing adolescents with $\mathrm{CD}$, and to refine them by taking into account $\mathrm{CD}$ subgroups such as with early onset and with callous-unemotional traits.

All significant differences between the CD and non-CD groups were observed on self-report measures, while none were found for performance tasks, which might be in part due to shared method variance, since $C D$ was self-reported. However, both performance tasks investigated "cold executive functions", i.e. performances obtained outside emotional activation, while the significant self-report measures concentrated on situations of negative affect or stress, which is in line with a recent finding that decision-making (measured through performance tasks) is impaired in $\mathrm{CD}$ adolescents under conditions of emotional arousal, but not outside of it ${ }^{13}$.

Other limitations of the present study are its sample composed exclusively of boys, restricting the generalization of its findings to girls with $\mathrm{CD}$, its cross-sectional design, which precludes ascertaining whether the observed deficits are antecedent of CD or mere concomitants, and its limited sample size, which did not allow us to assess the indepen- dent impact of school dropout, on which the two groups differed. Another point is that CD was assessed by self-report questionnaire, which can be sensitive to social desirability bias and lead to restricted reliability, compared with multiple informants' reports. Nevertheless, a systematic comparison of youth and parent reports has shown the former to be more appropriate ${ }^{63}$, and police reports are known to overlook a number of offences ${ }^{64}$.

In conclusion, using a control group with a comparably high prevalence of most mental disorders and controlling for substance problematic use and depression, the present findings suggests $C D$ to be associated with stronger tendencies to act-out under negative affect, and to think in a self-defeating and rigid way when under stress, indicative of a dysfunction in specific emotional regulation and cognitive coping competencies. Consequently, skills training in these domains ${ }^{65,66}$ could constitute additional useful interventions in juvenile offenders with $\mathrm{CD}$, for example by teaching them tools to identify their negative emotional states before they reach high intensity levels, to reduce negative affect without acting-out, to maintain a positive self-image when under stress, and to "step back" and analyze the situation, before acting, when stressed.

\section{Acknowledgements}

The present study was funded by a grant from the Swiss National Science Foundation (no. 3200B0-109827, 2005-2007). The authors would like to thank the adolescents and the staff of the participating institutions for their kind cooperation, as well as Alexandra Jubin, Mathias Romailler, Pascal Weinguni, and Laura Udry-Jørgensen for their help in data collection, and Christina Moses Passini for carefully proofreading the manuscript. 


\section{References}

1. Fazel S, Doll H, Langstrom N. Mental disorders among adolescents in juvenile detention and correctional facilities: a systematic review and metaregression analysis of 25 surveys. J Am Acad Child Adolesc Psychiatry 2008; 47(9): 1010-1019.

2. Cunliffe T. Arresting Youth Crime - A Review of Social Skills Training with Young Offenders. Adolescence 1992; 27(108): 891-900.

3. Leiber MJ, Mawhorr TL. Evaluating the Use of Social Skills Training and Employment with Delinquent Youth. J Crim Justice 1995; 23(2): 127-141.

4. Beauchaine TP, Gatzke-Kopp L, Mead HK. Polyvagal Theory and developmental psychopathology: Emotion dysregulation and conduct problems from preschool to adolescence. Biol Psychol 2007; 74(2): 174-184.

5. Lueger RJ, Gill KJ. Frontal-Lobe Cognitive Dysfunction in Conduct Disorder Adolescents. J Clin Psychol 1990; 46(6): 696-706.

6. Lynam D, Moffitt T, Stouthamer-Loeber M. Explaining the relation between IQ and delinquency - class, race, test motivation, school failure, or self-control. J Abnorm Psychol 1993; 102(2): 187-196.

7. Clarizio HF. Conduct disorder: Developmental considerations. Psychol Sch 1997;34(3):253-265.

8. Messier LP, Ward TJ. The coincidence of depression and high ability in delinquent youth. J Child Fam Stud 1998; 7(1): 97-105.

9. Tranah T, Harnett P, Yule W. Conduct disorder and personality. Pers Individ Dif 1998; 24(6): 741-745.

10. Teichner G, Golden CJ. The relationship of neuropsychological impairment to conduct disorder in adolescence: A conceptual review. AggressiViolent Behav 2000; 5(6): 509-528.

11. Heaton RK. Wisconsin Card Sorting Test Manual. Odessa: Psychological Assessment Ressources; 1981.

12. Kim M, Kim J, Kwon J. Frontal P300 decrement and executive dysfunction in adolescents with conduct problems. Child Psychiatry Hum Dev 2001; 32(93): 106.

13. Fairchild G, van Goozen SHM, Stollery SJ, Aitken MRF, Savage J, Moore SC, et al. Decision making and executive function in male adolescents with early-onset or adolescence-onset conduct disorder and control subjects. Biol Psychiatry 2009; 66(2): 162-168.

14. Blair RJR. A cognitive developmental-approach to morality - Investigating the psychopath. Cognition 1995; 57(1): 1-29.
15. Dodge KA. The structure and function of reactive and proactive aggression. In: Pepler DJ, Rubin KH, editors. The development and treatment of childhood aggression. Hillsdale, NJ: Lawrence Erlbaum Associates; 1991. p. 201-218.

16. Mitchell D, Blair RJR. State of the art: Psychopathy. Psychologist 2000; 13: 356-360.

17. Dougherty DM. IMT/DMT Immediate Memory Task \& Delayed Memory Task: A research tool for studying attention and memory processes (Version 1.2), Computer Software Manual. Houston, Texas: Neurobehavioral Research Laboratory and Clinic, University of Texas Science Center; 1999.

18. Dougherty DM, Bjork JM, Harper RA, Marsh DM, Moeller FG, Mathias CW, et al. Behavioral impulsivity paradigms: a comparison in hospitalized adolescents with disruptive behavior disorders. J Child Psychol Psychiatry 2003; 44(8): 1145-1157.

19. Swann AC, Bjork JM, Moeller FG, Dougherty DM. Two models of impulsivity: Relationship to personality traits and psychopathology. Biol Psychiatry 2002; 51(12): 988994.

20. Mathias CW, Marsh-Richard D, Dougherty DM. Behavioral measures of impulsivity and the Law. Behav Sci Law 2008; 26: 691-707.

21. Thompson LL, Whitmore EA, Raymond KM, Crowley TJ. Measuring impulsivity in adolescents with serious substance and conduct problems. Assessment 2006; 13(1): 3-15.

22. Dickman SJ. Functional and dysfunctional impulsivity - Personality and cognitive correlates. J Pers Soc Psychol 1990; 58(1): 95-102.

23. Moeller FG, Barratt ES, Dougherty DM, Schmitz JM, Swann AC. Psychiatric aspects of impulsivity. Am J Psychiatry 2001; 158(11): 1783-1793.

24. White JL, Moffitt TE, Caspi A, Bartusch DJ, Needles DJ, Stouthamer-Loeber M. Measuring Impulsivity and Examining Its Relationship to Delinquency. J Abnorm Psychol 1994; 103(2): 192-205.

25. Dougherty DM, Dew RE, Mathias CW, Marsh DM, Addicott MA, Barratt ES. Impulsive and premeditated subtypes of aggression in conduct disorder: Differences in time estimation. Aggress Behav 2007; 33(6): 574-582.

26. Whiteside SP, Lynam DR. The Five Factor Model and impulsivity: Using a structural model of personality to understand impulsivity. Pers Individ Dif 2001; 30(669): 689.

27. Miller J, Flory K, Lynam D, Leukefeld C. A test of the four-factor model of impulsivity-related traits. P Perso Individ Dif 2003; 34(8): 1403-1418. 
28. Nemiah JC, Freyberger H, Sifneos PE. Alexithymia: A view of psychosomatic process. In: Hill OW, editor. Modern trends in psychosomatic medicine. London: Butterworths; 1976. p. 430-439.

29. Langevin R, Hare R. Psychopathie et alexithymie chez un groupe de jeunes contrevenants. Revue de Psychoéducation et d'Orientation 2001; 30(2): 227-236.

30. Zimmermann G. Delinquency in male adolescents: The role of alexithymia and family structure. J Adolesc 2006; 29(3): 321-332.

31. Epstein S. CTI Constructive Thinking Inventory professional manual. Psychological Assessment Resources, Inc. ed. Lutz: 2001

32. Mezzich AC, Tarter RE, Kirisci L, Hsieh YC, Grimm M. Coping Capacity in Female Adolescent SubstanceAbusers. Addict Behav 1995; 20(2): 181-187.

33. Teplin LA, Abram KM, McClelland GM, Dulcan MK, Mericle AA. Psychiatric disorders in youth in juvenile detention. Arch Gen Psychiatry 2002; 59: 1133-1143.

34. Ochsner KN, Gross JJ. The cognitive control of emotion. Trends Cogn Sci 2005; 9(5): 242-249.

35. Pessoa L. Cognition and emotion. Scholarpedia 2009; 4(1): 45-67.

36. Pedersen W, Mastekaasa A, Wichstrom L. Conduct problems and early cannabis initiation: a longitudinal study of gender differences. Addiction 2001; 96(3): 415-431.

37. Wichstrom L, Skogen K, Oia T. Increased rate of conduct problems in urban areas: What is the mechanism? J Am Acad Child Adolesc Psychiatry 1996; 35(4): 471-479.

38. Germain M, Guyon L, Landry M. Grille de dépistage de consummation problématique d'alcool et de drogues chez les adolescentes et les adolescents (DEP-ADO). Montréal: RISQ; 2000.

39. Landry M, Guyon L, Bergeron J, Provost G. Évaluation de la toxicomanie chez les adolescents. Développement et validation d'un instrument. Alcoologie et Addictologie 2002; 24(1): 7-13.

40. Bernard M, Bolognini M, Plancherel B, Chinet L, Laget J, Stephan P, et al. French validity of two substanceuse screening tests among adolescents: A comparison of the CRAFFT and DEP-ADO. J Subst Use 2005; 10(6): 385395.

41. Sheehan DV, Lecrubier Y, Sheehan KH, Amorim P, Janavs J, Weiller E, et al. The Mini-International Neuropsychiatric Interview (M.I.N.I.): the development and validation of a structured diagnostic psychiatric interview for DSM-IV and ICD-10. J Clin Psychiatry 1998; 59(Suppl 20): 22-57.
42. Raven J, Court J, Raven J. Progressive Matrices Standart (PM38). Oxford: Oxford Psychologists Press; 1998.

43. Greve KW, Stickle TR, Love JA, Bianchini KJ, Stanford MS. Latent structure of the Wisconsin Card Sorting Test: a confirmatory factor analytic study. Arch Clin Neuropsychol 2005; 20(3): 355-364.

44. Dougherty DM, Marsh DM, Moeller FG, Chokshi RV, Rosen VC. Effects of moderate and high doses of alcohol on attention, impulsivity, discriminability, and response bias in immediate and delayed memory task performance. Alcohol Clin Exp Res 2000; 24(11): 1702-1711.

45. Van der Linden M, d'Acremont M, Zermatten AN, Jermann F, Lari F, Willems S, et al. A French adaptation of the UPPS Impulsive Behavior Scale - Confirmatory factor analysis in a sample of undergraduate students. Eur J Psychol Assess 2006; 22(1): 38-42.

46. Taylor GJ, Ryan D, Bagby RM. Toward the development of a new self-report alexithymia scale. Psychother Psychosom 1985; 44(4): 191-199.

47. Loas G, Otmani O, Fremaux D, Lecercle C, Duflot M, Delahousse J. Etude de la validité externe, de la fidélité et détermination des notes seuils des échelles d'alexythymie de Toronto (TAS et TAS-20) chez un groupe de malades alcooliques. L'Encéphale 1996; 22: 35-40.

48. Loas G, Corcos M, Stephan P, Pellet J, Bizouard P, Venisse JL, et al. Factorial structure of the 20-item Toronto Alexithymia Scale Confirmatory factorial analyses in nonclinical and clinical samples. J Psychosom Res 2001; 50(5): 255-261.

49. Pihet S, Suter M, Halfon O, Stephan P. Psychometric porperties of the French translation of the Constructive Thinking Inventory. Submitted 2009.

50. American Psychiatric Association. The diagnostic and statistical manual of mental disorders. 4 ed. Washington, DC: American Psychiatric Association; 1994.

51. Lecrubier Y, Weiller E, Hergueta T, Amorim P, Bonora LI, Lépine JP, et al. M.I.N.I. Mini International Neuropsychiatric Interview. Version française 5.0.0 DSM-IV; 1998.

52. Conrad R, Wegener I, Imbierowicz K, Liedtke R, Geiser F. Alexithymia, temperament and character as predictors of psychopathology in patients with major depression. Psychiatry Res 2009; 165(1-2): 137-144.

53. Ebner-Priemer UW, Welch SS, Grossman P, Reisch T, Linehan MM, Bohus M. Psychophysiological ambulatory assessment of affective dysregulation in borderline personality disorder. Psychiatry Res 2007; 150(3): 265-275. 
54. Cornell DG, Wilson LA. The Piq Greater-Than Viq Discrepancy in Violent and Nonviolent Delinquents. J Clin Psychol 1992; 48(2): 256-261.

55. Walsh A, Petee TA, Beyer JA. Intellectual Imbalance and Delinquency - Comparing High Verbal and High-Performance Iq Delinquents. Crim Justice Behav 1987; 14(3): 370-379.

56. Blair RJR. Applying a cognitive neuroscience perspective to the disorder of psychopathy. Dev Psychopathol 2005; 17(3): 865-891.

57. Frick PJ, White SF. Research Review: The importance of callous-unemotional traits for developmental models of aggressive and antisocial behavior. J Child Psychol Psychiatry $2008 ; 49(4): 359-375$.

58. Loeber R, Farrington DP, Stouthamer-Loeber M, Moffitt TE, Caspi A, Lynam D. Male mental health problems, psychopathy, and personality traits: key findings from the first 14 years of the Pittsburgh Youth Study. Clin Child Fam Psychol Rev 2001; 4(4): 273-297.

59. Luengo MA, Carrillodelapena MT, Otero JM, Romero E. A Short-Term Longitudinal-Study of Impulsivity and Antisocial-Behavior. J Pers Soc Psychol 1994; 66(3): 542-548.

60. Tittle CR, Ward DA, Grasmick HG. Self-control and crime/deviance: Cognitive vs. behavioral measures. J Quant Criminol 2003; 19(4): 333-365.

61. Soloff PH, Lynch KG, Moss HB. Serotonin, impulsivity, and alcohol use disorders in the older adolescent: A psychobiological study. Alcohol Clin Exp Res 2000; 24(11): 1609-1619.

62. Hochhausen NM, Lorenz AR, Newman JP. Specifying the impulsivity of female inmates with borderline personality disorder. J Abnorm Psychol 2002; 111(3): 495-501.
63. Colins O, Vermeiren R, Schuyten G, Broekaert E, Soyez V. Informant agreement in the assessment of disruptive behavior disorders in detained minors in Belgium: A diagnosis-level and symptom-level examination. J Clin Psychiatry 2008; 69(1): 141-148.

64. Moffitt TE, Caspi A. Childhood predictors differentiate life-course persistent and adolescence-limited antisocial pathways among males and females. Dev Psychopathol 2001; 13(2): 355-375.

65. Fraser MW, Galinsky MJ, Smokowski PR, Day SH, Terzian MA, Rose RA, et al. Social information-processing skills training to promote social competence and prevent aggressive behavior in the third grade. J Consult Clin Psychol 2005; 73(6): 1045-1055.

66. Lochman JE, Wells KC. The coping power program for preadolescent aggressive boys and their parents: Outcome effects at the 1-year follow-up. J Consult Clin Psychol 2004; 72(4): 571-578.

Author for correspondence:

Sandrine Pihet

Service Universitaire de Psychiatrie de l'Enfant et de l'Adolescence

Unité de Recherche

Rue du Bugnon 25A

CH-1011 Laussanne

Switzerland

Phone: +41 (0) 213147492

Fax: +41 (0) 213147481

E-mail: Sandrine.Pihet@chuv.ch 